\title{
Formação de professores: $O$ desafio da prática
}

\author{
Teacher training: The challenge of practice \\ Formación de profesores: El desafío de la práctica
}

Recebido: 17/07/2021 | Revisado: 20/07/2021 | Aceito: 21/07/2021 | Publicado: 29/07/2021

\author{
Suely Bastos da Fonseca \\ ORCID: https://orcid.org/0000-0003-1536-7705 \\ Universidade de Cuiabá, Brasil \\ E-mail: suely_fonseca@hotmail.com \\ Cilene Maria Lima Antunes Maciel \\ ORCID: https://orcid.org/0000-0003-4606-802X \\ Universidade de Cuiabá, Brasil \\ E-mail: cilenemlamaciel@gmail.com
}

\begin{abstract}
Resumo
Este artigo trata-se de uma pesquisa de mestrado para o Programa PPGEn UNIC/IFMT, que procurou investigar se a qualificação na formação docente vem atingindo a proporção esperada para melhoria da aprendizagem dos alunos (as). Para tanto, se propôs um estudo de caso, com roteiro de entrevista realizado com 15 professores numa Escola Pública da Rede Municipal de Educação EMEB Osmar José do Carmo Cabral que atenda um total de 670 alunos e teve como objetivo, identificar a importância das práxis educativas no processo de desenvolvimento e aprendizagem dos alunos e refletir sobre as múltiplas linguagens que constituem o universo do auto formação continuada dos profissionais da educação no âmbito escolar. Num certo momento, justifica-se que este estudo é necessário para que professores reconheçam e utilizem as formações para subsidiar no ensino, utilizando-as como um aliado muito importante na construção do conhecimento. Na metodologia deste trabalho foi proposto uma abordagem metodológica qualitativa para análise e interpretação dos dados. A partir dos resultados parciais, a pesquisa evidencia a importância da formação; contudo, faz-se necessário que o trabalho docente seja um instrumento de atualização voltado a prática pedagógica a fim de contribuir para a melhoria da aprendizagem dos alunos.
\end{abstract}

Palavras-chave: Formação de professores; Ensino; Prática docente; Teoria e prática.

\begin{abstract}
This article is a master's research for the Program PPGen UNIC/IFMT, which sought to investigate whether qualification in teacher education has reached the expected proportion for improving student learning. Therefore, a case study was proposed, with an interview script conducted with 15 teachers in a Public School of the Municipal Education Network EMEB Osmar José do Carmo Cabral that serves a total of 670 students and aimed to identify the importance of educational praxis in the process of development and learning of students and to reflect on the multiple languages that constitute the universe of continuous self-training of education professionals in the school environment. At a certain point, it is justified that this study is necessary for teachers to recognize and use training to subsidize teaching, using them as a very important ally in the construction of knowledge. In the methodology of this work, a qualitative methodological approach was proposed for data analysis and interpretation. From the partial results, the research highlights the importance of training; however, it is necessary that the teaching work is an updating instrument aimed at pedagogical practice in order to contribute to the improvement of student learning.
\end{abstract}

Keywords: Teacher education; Teaching; Teaching practice; Theory and practice.

\section{Resumen}

Este artículo es una investigación de maestría para el Programa PPGen UNIC / IFMT, que buscaba investigar si la calificación en la formación de maestros ha alcanzado la proporción esperada para mejorar el aprendizaje de los estudiantes. Por ello, se propuso un estudio de caso, con guión de entrevista realizada a 15 docentes de una Escuela Pública de la Red de Educación Municipal EMEB Osmar José do Carmo Cabral que atiende a un total de 670 alumnos y tuvo como objetivo identificar la importancia de la praxis educativa en el proceso del desarrollo y aprendizaje de los estudiantes y reflexionar sobre los múltiples lenguajes que constituyen el universo de la autoformación continua de los profesionales de la educación en el ámbito escolar. En cierto punto, se justifica que este estudio sea necesario para que los docentes reconozcan y utilicen la formación para subsidiar la docencia, utilizándolos como un aliado muy importante en la construcción del conocimiento. En la metodología de este trabajo se propuso un enfoque metodológico cualitativo para el análisis e interpretación de los datos. De los resultados parciales, la investigación destaca la 
importancia de la formación; sin embargo, es necesario que la labor docente sea un instrumento de actualización dirigido a la práctica pedagógica para contribuir a la menor del aprendizaje de los estudiantes.

Palabras clave: Formación del profesorado; Docencia; Práctica docente; Teoría y práctica.

\section{Introdução}

\subsection{Formação Contínua: Uma necessidade docente}

A proposta de realizar este estudo surge a começar de razões contextuais e atuais e da importância de se investigar se a educação dos docentes vem atingindo a proporção esperada para a melhoria da aprendizagem dos alunos (as). E aliando-se a este, fato ao processo final de desenvolvimento do recorte da pesquisa de Mestrado do Programa PPGEn UNIC/IFMT. E que segundo Romanowski (2009 p. 138): A formação é uma exigência para os tempos atuais. Desse modo, pode-se certificar como os saberes docentes acontece em continuum, iniciada com a escolarização básica, que depois se complementa no curso.

A Lei de Diretrizes e Bases da Educação aborda sobre a formação de professores para atuação na educação básica, que é garantida pelos artigos 62 e 63, destacando que esta dar-se-á em curso de licenciatura, de graduação plena, em universidades e institutos superiores de educação, onde os institutos superiores de educação manterão cursos formadores de profissionais para a educação básica e programas de formação pedagógica para portadores de diplomas de educação superior que queiram se dedicar à educação básica, segundo orientações da nota técnica número 020/2014 do Ministério da Educação (BRASIL, 2016, $\mathrm{n}^{\circ}$ 9.394/1996).

Segundo Pimenta (2005), coloca que a educação, não só retrata e reproduz a sociedade, mas também projeta a sociedade desejada. Por isso, vincula-se profundamente ao processo civilizatório e humano. A autora complementa seu pensamento com a seguinte afirmação: enquanto prática pedagógica, a educação tem, historicamente, o desafio de responder às demandas que os contextos lhes colocam. Com o objetivo de analisar a formação partilhada da construção social e histórica do fundamento para que necessariamente perpassa por esta formação, optamos por fazer um recorte que vai das teorias educacionais desenvolvidas na escola com a formação docente e com às práticas desenvolvidas pelo professor no recinto escolar.

É neste direcionamento que apresento este trabalho e entendo que este Artigo proporcionará benefícios evidentes, pois envolve um assunto de interesse do grupo da escola percebendo a relevância que os Programas de Formações de professores irão proporcionar através desta pesquisa, alavancando com mais estímulo à carreira docente na expectativa de melhorar a qualidade do ensino para os alunos.

\subsection{A Educação em Serviço e as suas transformações e ensinamentos}

É pertinente relatar algumas idéias com intuito de contextualizar este trabalho, bem como destacar alguns autores exíminos como Gatti (1997), Tardif (2008), Imbernón (2011) e Libâneo (2013), que contribuem e discutem este tema recorrendo a metodologias investigativas que relacionam aos fatores pertinentes para a metodologias de ensino, saberes docentes, mediação pedagógica, teoria demasiada, ausência de práxis, despreparo docente, assim como uma formação inicial deficitária.

Mas percebe-se que a composição introdutória de professores, repercute nas ações iniciais da profissão, e consequentemente, como a sociedade se modifica com o passar dos anos, o mesmo acontece com o trabalho do mediador, que tende a buscar melhorias para que em certos momentos suas ações possam ser construídas em prol da sociedade. Mas conforme Imbernón (2011) a ação docente cerne de todo processo de estudos e reflexões e que em meio a tanta evolução, esse docente não poderá mais beber na fonte da mera transmissão dos conhecimentos de ensinar apenas o básico e produzir o conhecimento autoritário.

Em seu pensamento o autor também comenta que se os seres humanos se tornaram mais complexos, a profissão docente também deverá se tornar. Este saber ensinar, refletir suas ações e buscar compreender, só se atinge com um processo permanente de formação de professores (Imbernón, 2011), o que colabora para o processo de desenvolvimento profissional docente. 
Para Tardif (2008) muitas das concepções teóricas aportadas na cultura de docente podem ter sido concebidas sem relação ao ensino e fora da essência do trabalho do educador, que mediante a sua proposta de nas carreiras de formação os alunos sejam reconhecidos como sujeitos dos fundamentos e transformadores em suas ações, que não sejam limitados a receber conhecimentos disciplinares e informações procedimentais, que se realize um trabalho no qual se abracem as expectativas cognitivas, sociais e afetivas, ou seja, a subjetividade para sua autonomia.

Ao abordar sobre os profissionais docentes que atuam nas dependências da escola, e sobre seus saberes na perspectiva de Tardif (2011) os saberes e experienciais são resultado de um processo de construção individual, mas, ao mesmo tempo, são compartilhados e legitimados por meio de processos de socialização profissional. Nesse sentido, a interação entre os professores desencadearia um processo de valorização e de reconhecimento desses saberes como saberes de uma classe e não de um profissional em específico.

São muitos os desafios o que torna a prática de ensinar cada vez mais complexa (Gatti, 1997, p. 21). Segundo Ens (2006):

Para superar uma formação fragmentada, tanto a instituição formadora de professores como os formadores e os futuros professores, precisam assumir que na "sociedade globalizada" se convive, simultaneamente, com a inovação e a incerteza. Por isso, a educação dos seres humanos se torna mais complexa, e a formação do professor, também, passa a assumir essa complexidade. Para superar a dicotomia entre ensino e pesquisa, teoria e prática, e possibilitar a construção de uma práxis dinamizada pela iniciativa, pelo envolvimento do futuro professor em projetos educativos próprios e fundamentados, torna-se necessário reconhecer tal complexidade (2006, p.12-13).

\subsection{Teoria, prática: habilidades principais a educação de docentes}

A prática nas direções de saberes do corpo docente, geralmente, acontece de maneira aplicacionista, assim como pontua Tardif (2008), ainda nesta perspectiva o autor aborda que por este processo os alunos passam alguns anos assistindo aulas baseadas em disciplinas que muitas vezes são repetitivas e desinteressantes, para depois, ou concomitantemente, aplicarem esses conhecimentos.

Por este percurso, estes aspectos se colocam de maneira distinta, constitui-se uma falsa reprodução dos saberes profissionais em relação à prática, mas que a acerca das idéias entre os saberes e estilo de maneira mais integrada ajudaria a ter uma visão mais

[...] globalizada do trabalho coletivo de cada ato de ensino, sempre confrontada e reconstruída pela devida prática e pelo trato com os problemas concretos dos contextos sociais em que se desenvolvem, poderia ser a chave de toque que acionaria uma certa perspectiva metodológica. (GATTI, 1997, p. 57).

Ainda nesta perspectiva é importante esclarecer que o conceito e o saber devem caminhar juntos e não serem consideradas uma consequência da outra. Pimenta (1999), destaca que a respeito dos saberes é que se idealizam à docência que podem ser destacados pela experiência, pelo conhecimento e pelo pedagógico.

Pimentel (2014), salienta que é fundamental quão os conhecimentos teóricos tenham sentido e significado para que se possa perceber a analogia acerca do raciocínio e das ações cotidianas.

Podemos também aqui comentar sobre o conhecimento originário que pode ser um momento especial para discernir área de desempenho do formador e suas especificidades, porém, ser realista e assumir que ela não consegue dar conta de toda a complexidade da profissão é imprescindível.

Neste sentido, Tardif (2008), postula qual os docentes se inserem no seu ambiente de trabalho mesmo antes de começar a carreira profissional, pois passam vários anos como estudante, isso pode influenciar veementemente a prática que este professor irá adotar. 
O autor também destaca a flexibilidade como um aspecto essencial ao planejamento, onde busca refletir sobre todo o direcionamento da sua prática pedagógica, com vistas a atender as necessidades encontradas pela sociedade, compreendendo que; o processo de ensino é vivo e pode sofrer modificações que poderá propiciar uma melhor performance do professor, a fim de valorizar na sua prática cotidiana.

E acerca a ligação entre professor e aluno, Libâneo (2013), aponta que nessa relação existem importantes processos cognoscitivos, que podem ser percebidos na ação de ensinar do docente, e, socioemocionais, que são referentes aos vínculos afetivos, estabelecidos entre o professor e os alunos e as normas que regem as condutas.

Sendo assim, destacamos nas palavras de Freire (2008):

"Não há ensino sem pesquisa e pesquisa sem ensino. Esses que fazeres se encontram um no corpo do outro. Enquanto ensino, continuo buscando, reprocurando. Ensino porque busco, porque indaguei, porque indago e me indago. Pesquiso para constatar, constatando intervenho, intervindo educo e me educo. Pesquiso para conhecer o que ainda não conheço e comunicar ou anunciar a novidade" (Freire, 2008, p.29).

De acordo com Tardif (2008), muitas das concepções teóricas aportadas na construção dos educadores podem ter sido concebidas sem relação ao ensino e fora da atitude preceptoral. Isto pode fazer com que estes conhecimentos não sejam úteis no momento da atuação efetiva na sala. Contudo, ele aponta que, talvez, eliminar a lógica disciplinar não seja o caminho.

Sua proposta é que nas formações do corpo docente, os alunos sejam reconhecidos como sujeitos da sabedoria, o qual não sejam limitados a receber conhecimentos disciplinares e informações procedimentais, que se realize um trabalho no qual se abracem as expectativas cognitivas, sociais e afetivas, entre outras palavras, a subjetividade.

“O principal desafio para os saberes docentes, nos próximos anos será o de abrir um espaço maior para os conhecimentos práticos dentro do próprio currículo" (Tardif, 2012, p. 241).

Tomo como base para esta reflexão a importância para uma amplitude dos saberes, tendo como uma das raízes de idéias de Dewey (1976), que trata a forma ao conhecimento do professor fundamental para entender a atuação de cada um dentro deste universo coletivo, desenvolvido pela e para a escola permitindo com que este profissional melhore em sua prática docente.

Imbernón (2011), infere que os estudos de situações problemas deveriam ser abrangidos nos currículos escolares promovendo os estudos do cotidiano, os percursos realizados pelos professores, as ações e as estratégicas caso fossem necessárias e importantes para a construção do conhecimento.

Portanto, a experimentação da prática em consonância com a teoria, proposta no curso de organização introdutório de professores são de suma importância para uma boa formação profissional. Entretanto, para que isso aconteça o professor precisa se sentir sujeito da sua aprendizagem e das suas múltiplas relações enunciativas, e sentir a escola como lugar de crescimento profissional permanente.

Mas isso não tem sido uma tarefa muito fácil para os professores, pois a garantia de viver num exercício de democratização continua sendo uma luta árdua para esses profissionais que conhecem diariamente as incertezas deste novo século.

Com estes esclarecimentos, Freire tenta apresentar esta luta estruturando com o texto, destacando:

[...] o grande problema que se coloca ao educador ou à educadora de opção democrática é como trabalhar no sentido de [...] que a necessidade do limite seja assumida eticamente pela liberdade [...] uma pedagogia da autonomia tem de estar centrada em experiências estimuladoras da decisão e da responsabilidade, [...] em experiências respeitosas de liberdade. (Freire, 2008, p.118-121) 


\section{Materiais e Métodos}

Esta é uma pesquisa de natureza qualitativa que foi desenvolvida em uma Escola Pública no Município de Cuiabá-MT, que atende 670 alunos desde a Educação Infantil, e o 1 Ciclo do Ensino Fundamental. Foram entrevistados quinze (15) profissionais, sendo oito (8) professores em unidocência, três (3) de Educação Física, (2) em Artes e Educação, uma (1) coordenadora pedagógica e uma (1) diretora. Os professores foram entrevistados, tendo suas falas gravadas para análise posterior. Acerca do relato diante da entrevista de gravação, Bauer e Gaskell (2012) salientam que esta seja individual, pois exige um tempo para ser realizada, sendo que, para sua realização, o entrevistador pode utilizar de dispositivo que contenha, os temas centrais, bem como tal dispositivo, poderá servir como norteador para a realização do trabalho.

Sendo uma pesquisa de Mestrado do Programa PPGEn UNIC/IFMT, apresenta uma metodologia de caráter qualitativa tendo um panorama de interesse coletivo a fim de investigar intensamente as considerações para que apareçam perante as evoluções os elementos apurados. Para Creswell (2003) esta atitude será primordial a fim de permitir melhorar no aperfeiçoamento deste referido estudo.

E para Sampaio e Mancini (2007), este tipo de pesquisa qualitativa se dá mediante a análise da literatura disponível em bases de dados específicas e segue regras de organização rigidamente pré-estabelecidas.

Para tanto, esta pesquisa, passar-se-á, pelo processo de dados, ainda que utilizada das informações obtidas pelas entrevistas realizadas com os professores, coordenadora pedagógica e diretora embasadas pelas teorias.

Dessa forma, para realizar a categorização das informações obtidas tanto pelos professores, coordenação e direção, utilizar-se-á o método de análise de conteúdo da pesquisa.

Acerca do método de análise de pesquisa de conteúdo, Bardin (2016, p.31), o tem configurado como um certo complexo de técnica eficazes, que possibilita analisar as comunicações com o intuito de extrair elementos que permite estabelecer um julgamento onde assevera como "nunca se trata de um instrumento, mas de um leque de apetrechos; ou seja, com maior rigor, será um único instrumento, mas marcado por uma grande disparidade de formas sendo adaptável a um campo de aplicação muito vasto", neste caso, as entrevistas que também são classificadas de comunicações. A autora ainda enfatiza que:

A análise de conteúdo aparece como uma equipe de técnicas de análise das comunicações, que utiliza procedimentos sistemáticos e objetivos de descrição do conteúdo das mensagens. [...] a intenção da análise de conteúdo é a inferência de conhecimentos relativos às condições de produção, ou inferência que recorre a indicadores. (Bardin, 2016, p. 38).

Para a realização do estudo dessa pesquisa, em primeiro momento utilizou-se as informações obtidas via roteiro de entrevista semiestruturados respondidos pelos professores, coordenadora e diretora. (Quadros 1 e 2).

\section{Quadro 1. Roteiro de entrevista para os professores.}

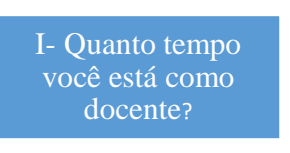

II- Qual o motivo
que te levou a
escolher a carreira
de docente?

III- Qual a mudança que
você vem percebendo em
relação ao ensino e
aprendizagem dos alunos
nos dias de hoje?

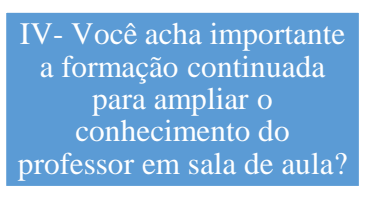




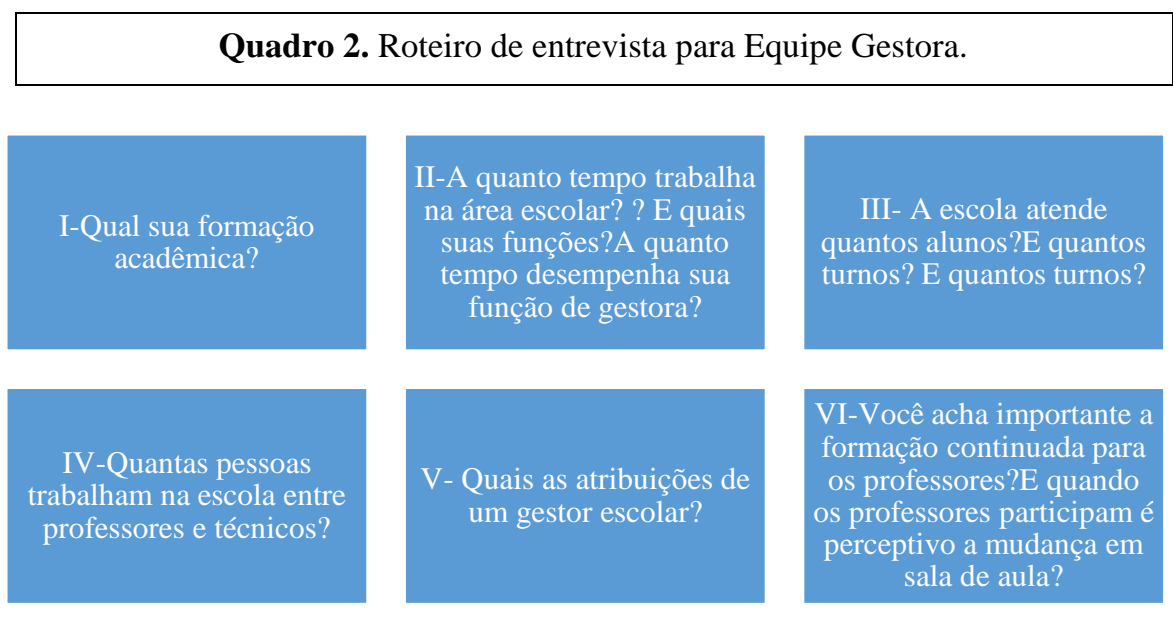

Fonte: Autores.

Por esta ser uma pesquisa que lida com seres humanos, de tipologia exploratória, teve seu projeto submetido e aprovado pelo Comitê de Ética CEP, em consenso com as atribuições definidas na Resolução CNS nº 466 de 2012 e na Norma Operacional $\mathrm{n}^{\circ} 001$ de 2013 do CNS.

\section{Resultados e Análise dos Dados}

Mediante este estudo os resultados e discussões foram evidenciadas e caracterizadas de forma descritiva tendo conforme sugestão de trabalho apresentar a análise dos conceitos reunidos em entrevista semiestruturada realizado pelos participantes, sujeitos dessa discussão. E retratadas as informações inerentes das análises realizadas dos relatos obtidos por segmentos pelos profissionais entrevistados.

Entre os métodos, utilizou-se o método da análise do conteúdo, Bardin (2016), e posteriormente se procedeu com a análise das informações pelo processo da codificação, seguida pela categorização, tendo por base as respostas e entrevistas gravadas com roteiro semiestruturado tanto dos professores, com a coordenação e direção.

É importante relatar que o objeto dessa pesquisa foi configurado dentro do processo para melhoria de ensinoaprendizagem, como os educadores, coordenadora e diretora são oriundos das redes públicas do Município de Cuiabá.

E como forma de obter informações que possibilitassem a realização da mesma, utilizou-se da tipologia exploratória, sendo estruturada por um roteiro de entrevistas, que possibilitasse nortear a gravação individual dos entrevistados.

Anteriormente, foi realizado um roteiro de entrevista semiestruturado com 15 profissionais, sendo eles: dez (10) professores unidocência, (3) Educação Física, (2) Arte e Educação uma (1) coordenadora e uma (1) diretora. Dentre os professores, treze (13) trabalham com estudantes da Educação Infantil e Ensino Fundamental. Quanto os outros (02) integrantes a coordenadora e a diretora com todas as turmas.

Nessa primeira parte da análise, foram apresentados e discutidos os dados inerentes à categoria local de realização da formação permanente de educadores apresentando onde ela acontece. 
Figura 1-Categorias de Análise

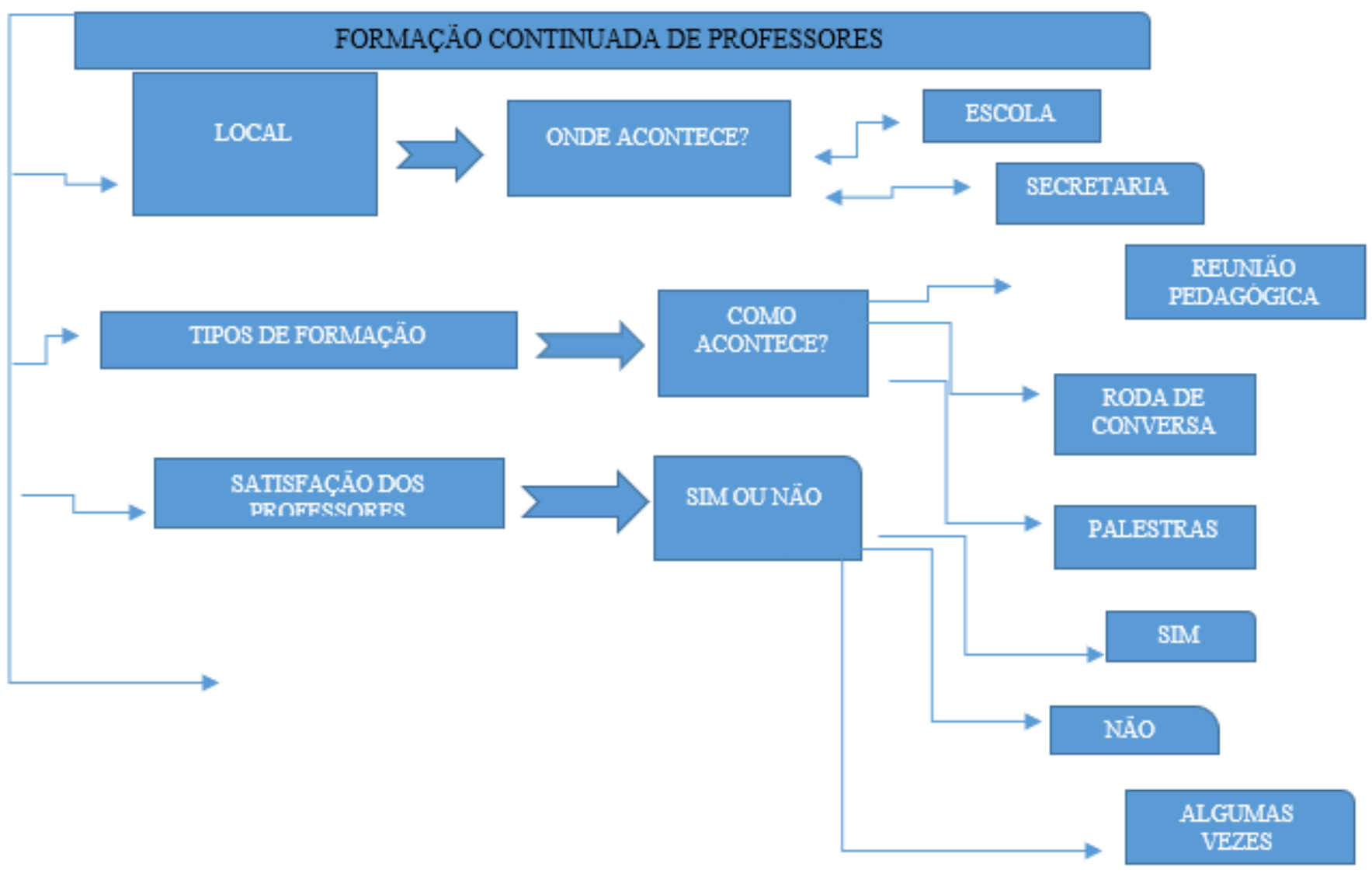

Fonte: Autores (2021).

No segundo momento, foram trabalhados com a categoria sobre como acontece as formações. No terceiro momento, a ação referente a análise foi realizada levando em consideração a categoria com o grau de satisfação, tendo por base o quesito satisfação dos docentes em comparação, a forma como é realizado o momento de formação continuada; sendo que nessa última parte de conciliação com o propósito de observar se a formação ao ser realizada, satisfez ou não aos anseios dos professores.

\subsection{Apresentação da categoria: tipos de formação continuada}

Quando os professores foram indagados a respeito de como o conhecimento constante acontece, $80 \%$ deles disseram que esta acontece nas rodas de conversa e ou sala de saberes e, $15 \%$ deles disseram que a educação continuada acontece em palestras, enquanto que $5 \%$ deles disseram que o desenvolvimento de saberes acontece em reunião pedagógica. Dentre os entrevistados todos são de Cuiabá. 
Figura 2 - Representação da categoria: tipos de formação continuada.

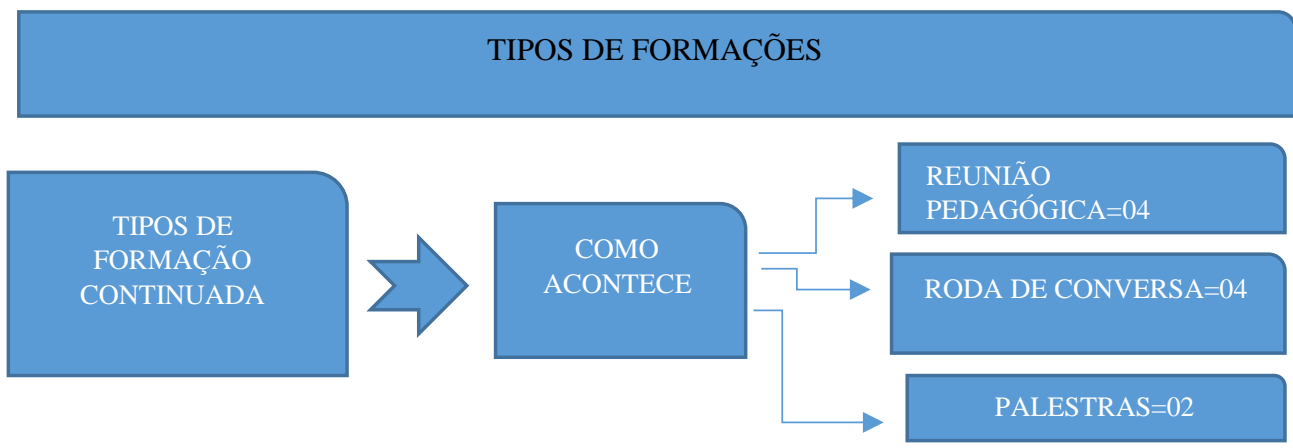

Fonte: Autores (2021).

Em consenso com a visão de Candau (1997), tanto como Demo (2002), quanto para Imbernòn (2011), há várias concepções inerentes aos momentos destinados à formação continuada e com diversas denominações.

Nessa categoria o grupo entrevistado de professores, apresentaram como acontece a estruturação do conhecimento. Expondo suas ponderações, claras e definidas. E quando foram indagados a respeito sobre como a construção consecutiva dentre os educadores é realizada, disseram que:

"Acontece nas rodas de conversas" (P 8).

“Algumas palestras são apresentadas para subsidiar nossas formações” (P 10).

"Nas reuniões pedagógicas também acontecem formações pois sempre é convidado alguém que domine determinado assunto” (P 6).

Constata-se ainda que o conhecimento permanente destes professores, acontece em vários momentos e isso é de extrema relevância. No entanto, ao acontecer a formação, assim, como nos fora reportado pelos entrevistados, deve-se atentar para que não haja desfoque, pois se tratando de reuniões pedagógicas, rodas de conversa e ou oficinas, há possibilidades de se discutirem assuntos de pouca relevância.

Às vezes, nem todos os assuntos discutidos nesses momentos são inerentes ao planejamento pedagógico. No entanto, de acordo como Tardif (2012), é impossível conceber uma formação sem considerar os interesses dos professores, quanto as fontes formativas, momentos e realidade.

Franco (2012), adverte com a intenção para refletir a respeito da formação acontecer de várias formas, com diversas conotações, para não se efetuar no vácuo, por isso, precisa se encontrar vinculada ou direcionada para algo prático, com objetivo estipulado.

Diante da concordância desta situação, Nòvoa na década de noventa e Alarcão (2011), afirmam como a instrução pode servir para estimular a progressão responsável dos professores, promover autonomia contextualizada, no sentido não só de ver as necessidades do sistema escolar, não obstante toda via, as possibilidades quão aparem estar criadas almejando o sucesso do sistema de educação-aprendizagem.

Dever-se-á então, entender qual o desenvolvimento incessante de professores, ao se construir processualmente por diversos momentos, torna-se necessária e permanente com início no âmbito acadêmico, tendo como efeito, melhores resultados no/com serviço do magistério. 


\subsection{Apresentação da categoria: grau de satisfação dos professores sobre a educação frequente}

Como já foram apresentadas as duas primeiras categorias, abordando os locais de realização da formação, tipos de formação continuada, nessa última categoria apresentar-se-á o grau de satisfação dos educadores em correlação à formação continuada, trazendo seus posicionamentos a respeito da forma como ela acontece. Sendo que para a realização dessa categoria, assim como nas demais ora apresentadas, também serão consideradas as informações advindas dos professores entrevistados.

Figura 3 - Representação da categoria: grau de satisfação dos professores.

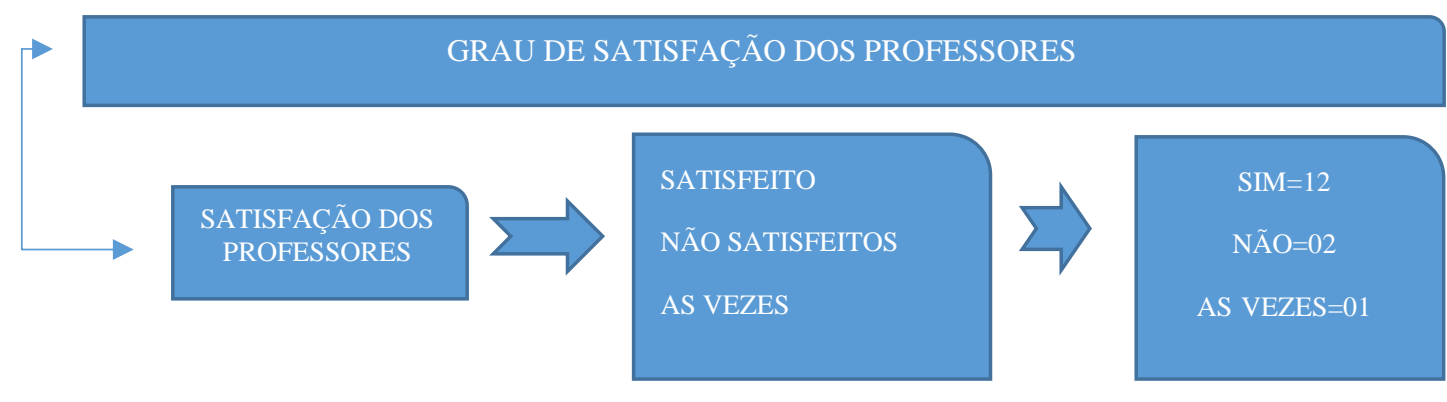

Fonte: Autores.

Diante disso, quando os professores foram questionados sobre o conhecimento frequente, realizada para eles, $85 \%$ disseram ser satisfatória, $10 \%$ dos entrevistados disseram que não era satisfatória, e 5\% apontando as vezes. Os motivos que chegaram a essa satisfação acerca da ligação da formação seria para que o educador consiga contribuir no método de instrução para aprendizagem de seus alunos, e também no seu próprio desenvolvimento enquanto profissional, manifestando sobre perspectiva que os impactos dessa qualificação podem ser poderosos em todo processo de aprendizagem dos alunos, de melhorar a qualidade dos conteúdos ministrados nas dependência da escola e estando mais preparado e informados sobre técnicas para atender, abordar conteúdos e conduzir com eficiência uma aula. Entre os motivos alegados pelos entrevistados de não serem satisfatória ou as vezes, seria sobre escolha dos temas a serem abordados, horário que muitas vezes já saem de uma carga de trabalho extensa e sobrecarregada, sendo que nem sempre tais temas escolhidos estão e/ou são em conciliação em relação a realidade da escola. E quando indagados, sobre quais seriam os motivos, que alegaram a formação para professores fossem satisfatórias disseram que:

"Com as formações consegui absorver a magnitude da elaboração do curso, logo foi fundamental para toda organização para que concorde com a construção e o ensinamento”. (P 7).

"Pois conversamos com os alunos e relacionar com elas foram primordial suporte durante minha aprendizagem" (PROFESSOR 3).

"Compreendi o essencial significado da aprendizagem pois pratiquei com forte vigor esta aquisição, memorizei valores como nunca recordava como antes" (PROFESSOR 2).

"Aprendi ainda que fundamentos é primordial em relação ao desempenho na destreza da prática" (PROFESSOR 5). "As formações permitiram que, nós professores, estivéssemos mais sensíveis quanto ao modo de ensinar. Esse estudo permitiu termos mais segurança quando de fato assumimos recinto escolar" (PROFESSOR 9).

Entretanto, Moran (2007), considera que um dos eixos das mudanças na educação passa pela transformação da educação em um sistema de comunicação autêntica e aberta entre professores e alunos, principalmente, incluindo também administradores e a comunidade, principalmente os pais.

Diz Moran (2007, p. 1): 
Só vale a pena ser educado dentro de um ambiente comunicacional participativo, interativo, vivencial. Só aprendemos profundamente dentro desse contexto. Não vale a pena ensinar dentro de estruturas autoritárias e ensinar de forma autoritária. Pode até ser mais eficiente a curto prazo - os alunos aprendem rapidamente determinados conteúdos programáticos - mas não aprendem a ser pessoas, a ser cidadãos.

Cabe a cada um de nós a busca pela atualização, seja participando de cursos presenciais ou à distância, seja pela pesquisa que é uma das maneiras de formação continuada.

Para Freire (2002, p. 32):

Enquanto ensino continuo buscando, reprocurando. Ensino porque busco, porque indaguei, porque indago e me indago. Pesquiso para constatar, constatando, intervenho, intervindo educo e me educo. Pesquiso para conhecer o que ainda não conheço e comunicar ou anunciar a novidade.

Para Nòvoa (1992), a construção assídua de professores necessita ser considerada como o momento chave da capacitação profissional, articulando-se com o desenvolvimento da sociedade. Contudo, em consenso junto as respostas dos entrevistados, essa ainda jamais será algo na realidade da educação pública do Município de Cuiabá, conforme pontuado por alguns componentes do diagnóstico. De forma direta, quando indagados, sobre quais seriam os motivos, que fazia a qual a instrução fosse insatisfatória ou as vezes não atendia disseram que:

“Os cursos não vem apresentando a execução dos saberes necessários nessas formações” (P 1).

"Não vem atendendo com legitimidade os temas que são trabalhados na escola" (P 4).

"Pudessem pensar em horários diferenciados, pois já estamos exaustos quando vamos para as formações” (P 11).

Nòvoa (1992), ainda enfatiza, que tal impasse só poderá ser resolvido se o ensino contínuo dos docentes for refletido de educadores para educadores e em locais determinados; de forma a considerar as subjetividades, tantos dos profissionais, quantos dos locais em que as formações são realizadas.

Segundo Tardif (2012), salienta que mais do que nunca a educação incessante para educadores precisa ser repensada nesse novo século, pois devido sua importância no sentido de instrumentalizar o professor para o funcionamento do ensino a vivência destes aspectos, ainda a construção de novos saberes precisa ser primordial na formação humana considerando o aprimoramento para o movimento do ensino, pois tal atitude permitirá ao professor rever sua conduta e conhecimentos para que possam atuar de uma maneira contextualizada, em relação ao tempo e espaço.

\section{Considerações}

Através deste trabalho continuarei investigando os resultados obtidos com esta pesquisa através das experiências vivenciadas e aprofundando para contribuir para aprimoramento do conhecimento docente, pois maiores serão os desafios que o profissional enfrentará ao longo de sua trajetória, mas continuar desenvolvendo práticas pedagógicas importantes para o desenvolvimento deste profissional serão intervenções indispensável para que haja maior mobilização numa organização docente.

Logo, contemplar sobre a educação docente cria um movimento fundamental, sobretudo como concerne à construção original tanto nas práticas pedagógicas quanto na valorização de todos os profissionais envolvidos.

Deste modo a pesquisa ocorrida evidencia qual a imergência do saber no tempo da construção que é importante durante a educação, com todo preceptor arguidor, inovador, cauteloso, soberano, o que considera a opinião quanto ambiente particular, mas que percebe a vontade do aprendizado infinito no que compete aos argumentos curriculares. 
Neste sentido, Freire (1996) ainda ensina que a relação de respeito à dignidade e às particularidades do educando se dá via dialógica, toda hora de apenas por meio do diálogo, e de uma boa intercomunicação professor-educando, é que se torna possível alcançar os objetivos esperados, de forma a gerar, espontaneamente, uma relação afetiva, haja vista quão, educadores sempre deve buscar por modo dentre sua fala, assim como, em suas ações e em suas gestões, trazer o aluno para perto de si e do objeto do conhecimento, sendo justamente isso, que tornará sistema com ensinamento-aprendizagem mais instigante e, por consequência motivador.

\section{Referências}

Alarcão, Isabel. Professores reflexivos em uma escola reflexiva. 8 ed. São Paulo: Cortez, 2011

Bardin, L. (2016). Análise de conteúdo: edição revista e ampliada. São Paulo: Edições 70.

BAUER, Martin W.; GASKELL, George (org.). Pesquisa qualitativa com texto, imagem e som: um manual prático. Petrópolis: Vozes, 2002. 448 p.

Brasil, Lei de Diretrizes e B. Lei nº 9.394/96, de 20 de dezembro de 1996.

Candau, Vera Maria. Formação Continuada de Professores: Tendências Atuais. In: (Org.). Magistério: construção cotidiana. Petrópolis: Vozes, 1997.

Creswell, J. W. (2003). Projeto de pesquisa: métodos qualitativo, quantitativo e misto. 2. ed. Porto Alegre: Artmed. 248 p.

Demo, P. (2002). O professor e seu direito de estudar. In: Neto, A. S.; Maciel, L. S.B. Reflexões sobre a formação de professores. Campinas, SP: Papirus.

Dewey, J. (1976). Experiência e educação. 2. ed. São Paulo: Ed. Nacional.

Flick, U. (2009). Introdução à pesquisa qualitativa. 3. ed. Porto Alegre: Artmed.

Franco, Maria Amélia Santoro. Pedagogia e prática docente. São Paulo: Cortez, 2013.

Freire, P. (1996). Pedagogia da autonomia: saberes necessários a prática educativa. 25ª ed. São Paulo: Paz e Terra.

Freire, Paulo. Pedagogia da autonomia: saberes necessários à prática educativa. São Paulo: Paz e Terra, 2002.

Freire, P. Pedagogia da autonomia: saberes necessários à prática educativa. 37. ed. São Paulo: Paz e Terra, 2008.

Freitas, H. C. L. Formação de professores no Brasil: 10 anos de embate entre projetos de formação. Educação \& Sociedade, v. 23, n. 80, p. 137-168, Campinas, set. 2002 .

Gatti, B. (1997). Formação de professores e carreira: problemas e movimentos de renovação. Campinas, SP: Editora Autores.

Imbernón, F. (2011). Formação docente e profissional: formar-se para a mudança e a incerteza. 9. ed. São Paulo: Cortez.

Libâneo, J. C. (2013). Didática. 2. ed. São Paulo, SP: Cortez.

Marconi, M. A., \& Lakatos, E. M. (2017). Fundamentos de Pesquisa Científica. 8. Ed. São Paulo: Atlas.

Moran, J. M. (2007). A educação que desejamos. Modificar a forma de ensinar. A aprendizagem de ser educador. As etapas de aprendizagem a ser docente. Educar o educador. www.eca.usp.br.

Nóvoa, Antonio (Org.). Os professores e a sua formação. Portugal, Lisboa: Publicação Don Quixote. Instituto de Inovação Educacional, 1992.

Pimenta, S. G. (2005). O estágio na formação de professores-unidade teoria e prática? São Paulo: Cortez.

Pimenta, Selma Garrido (Org.). Saberes Pedagógicos e Atividade Docente. São Paulo: Cortes, 1999

Pimentel, E. F. (2014). A epistemologia e a formação docente: reflexões preliminares. In: Ramalho, B. L.; Nunes, C. P.; Crusoé, N. M. C. (org.). Formação para a docência profissional: saber e práticas pedagógicas. Brasília: Liber Livro.15-38 p.

Romanowski, J. P. (2007). Formação e Profissionalização docente. Curitiba: Ibpex, 2007. Loiola, R. (2009). Formação continuada. Revista nova escola. São Paulo: Editora Abril no: 222.138 p.

Sampaio, R. F.; Mancini, M. C. Estudos de Revisão Sistemática: um guia para síntese criteriosa da evidência científica. V. 11, n. 1. São Carlos-SP: Revista Brasileira de Fisioterapia, p. 83-89, 2007.

Schon D. A. Formar professores como profissionais reflexivos. In: NÓVOA, A. (org.). Os professores e a sua formação. 2. ed. Lisboa: Instituto de Inovação Educacional, 1995. pp.79-91.

Tardif, M. (2008). Saberes docentes e formação profissional. 14 ed. Petrópolis: Vozes. 
Research, Society and Development, v. 10, n. 9, e40710918352, 2021

(CC BY 4.0) | ISSN 2525-3409 | DOI: http://dx.doi.org/10.33448/rsd-v10i9.18352

Tardif, M. (2012). Saberes docentes e formação profissional. 10. ed. Petrópolis: Vozes.

Westbrook, R. B., \& Dewey, J. (2010). Recife, PE: Fundação Joaquim Nabuco: Massangana. 